\title{
Efeito de dentifrícios branqueadores sobre a superfície do dente, rugosidade e cor de dentes pigmentados por fumaça de cigarro
}

André R Di Spagna (IC), Juliana C Públio (PG), Waldemir F Vieira-Junior (PG), Flávio H B Aguiar (PQ), Débora A N L Lima (PQ)

\section{Resumo}

A fumaça de cigarro tem potencial em pigmentar à estrutura dental. $\mathrm{O}$ escurecimento dental tem levado pacientes a buscarem o uso de dentifrícios branqueadores comerciais. Entretanto, a associação destes dentifrícios e sua possível efetividade clareadora no esmalte dental exposto à fumaça de cigarro são desconhecidas.

Palavras Chave: dentifrícios branqueadores, rugosidade, cor.

\section{Introdução}

O efeito de dentifrícios branqueadores no esmalte previamente exposto à fumaça de cigarro ${ }^{1}$ é desconhecido, uma vez que esses dentifrícios possam causar perda de estrutura dental sadia decorrentes aos abrasivos em sua composição ${ }^{2}$. Esse estudo avaliou o efeito desses dentifrícios na estrutura dental através de análise da rugosidade superficial ( $R a$ - rugosímetro) e das propriedades cromáticas (CIE L*a* $b^{*}$ - espectrofotometria de reflectância) do esmalte.

\section{Resultados e Discussão}

Blocos de esmalte/dentina $(n=10)$ foram expostos: 1) $\mathrm{CN}$ - Ciclo de exposição à fumaça do cigarro (EFC) + Ciclo de 3 meses (C) de escovação com água purificada (controle) em máquina simuladora de escovação; 2) MP- EFC + $C$ de dentifrício convencional, Colgate ${ }^{\circledR}$ Máxima Proteção (1450 ppm F); 3) WN- EFC + C de Close up $^{\circledR}$ White Now; 4) LW- EFC + C de Colgate ${ }^{\circledR}$ Luminous White; 5) CT- EFC + C de Colgate $^{\circledR}$ Total 12 professional whitening; 6) CS- EFC + C de Colgate ${ }^{\circledR}$ Pró-Alívio Branqueador. Os dados foram submetidos à ANOVA "one way" e Tukey $(\alpha=0,05)$. Todos os grupos demostraram aumento da Ra quando EFC. Quando associado aos tratamentos a Ra do esmalte foi aumentada (MP, CT e CS), diminuída (LW), ou inalterada ( $\mathrm{CN}$ e WN). $\mathrm{Na}$ análise de cor, LW apresentou $\Delta \mathrm{E}$ estatisticamente diferente $(p<0.05)$ de $C N$, e $W N$ apresentou aumento de luminosidade $(\Delta \mathrm{L})$ do esmalte. Os tratamentos não interferiram em $\Delta \mathrm{a}$, não diferindo estatisticamente entre si. CS apresentou um maior valor de $\Delta b$ (inicial $x$ final) diferente estatisticamente $(p<0.05)$ de $C N$, demostrando alteração positiva no eixo $b^{*}$ (amarelo). Os dentifrícios apresentaram efeito nas propriedades cromáticas do esmalte fumado, para LW a alteração de cor foi perceptível entre os tempos (EFC $x$ Após $C$ ), e $W N$ no eixo $L^{*}$ que representa $o$ valor (eixo preto-branco) no mesmo tempo.

\section{Conclusões}

Colgate $^{\Theta}$ Luminous White e Close up ${ }^{\circledast}$ White Now não interferiram negativamente na rugosidade e ainda foi capaz de alterar a cor.

Colgate ${ }^{\circledR}$ Máxima Proteção, Total 12 e PróAlívio não foram capazes de promover alterações de cor clinicamente significantes, e ainda alterou as propriedades físicas do esmalte devido a abrasivos que aumentaram a rugosidade do esmalte em dentes expostos ao cigarro.

\section{Agradecimentos}

Ao Programa Institucional de Bolsas de Iniciação Científica - PIBIC

${ }^{1}$ Públio, J. C.; D’Arce, M. B.; Brunharo, N. M.; Ambrosano, G. M.; Aguiar, F. H.; Lovadino, J. R.; Lima, D. A. J Clin Exp Dent. 2013, 163,168 .

${ }^{2}$ Lima, D. A.; Silva A. L.; Aguiar, F.H.; Liporoni, P. C.; Munin, E.; Ambrosano, G. M.; Lovadino, J. R. Braz Oral Res. 2008, 106,111 . 